\title{
Análise e dimensionamento de vigas de seção " $L$ " de concreto pré-moldado utilizando o Método das Bielas
}

\author{
Analysis and design of precast concrete spandrel beams using the \\ Strut-and-Tie Method
}

\section{Análisis y diseño de vigas de sección " $L$ " de hormigón prefabricado usando Modelos de Bielas y Tirantes}

\author{
PALHARINI JUNIOR, Dionisio ${ }^{1}$ \\ SOUZA, Rafael Alves de ${ }^{2}$ \\ ${ }_{1}^{1}$ Programa de Pós-graduação em Engenharia Civil, Departamento de Engenharia Civil, Universidade Estadual de \\ Maringá, Maringá-PR, Brasil. dionisiopalharini@gmail.com \\ ORCID: 0000-0001-8616-7386 \\ 2 Programa de Pós-graduação em Engenharia Civil, Departamento de Engenharia Civil, Universidade Estadual de \\ Maringá, Maringá-PR, Brasil. rsouza@uem.br \\ ORCID: 0000-0002-9990-2850 \\ Recebido em 30/03/2020 Aceito em 06/05/2020
}




\title{
Resumo
}

Dentre os elementos presentes nas estruturas de concreto pré-moldado estão as vigas de seção "L", largamente utilizadas no perímetro (bordas e fachadas) das edificações. A geometria tridimensional e as cargas externas aplicadas excentricamente na aba lateral fazem com que este tipo de viga esteja submetido simultaneamente a tensões normais e tensões de cisalhamento, gerando assim um complexo estado tensional. $\mathrm{O}$ fato das ligações com os apoios também estarem submetidas a torção torna o projeto estrutural das vigas de seção "L" um dos mais complexos entre os elementos da indústria de concreto pré-moldado por particularidades que não ocorrem nos modelos de vigas convencionais. Nesse contexto, o presente artigo tem como objetivo apresentar a análise e dimensionamento de vigas de seção " $\mathrm{L}$ " utilizando o Método das Bielas. Para tanto, foi desenvolvido um estudo de caso com auxílio do software CAST contemplando todas as etapas de dimensionamento e respeitando os parâmetros recomendados pela ABNT NBR 6118:2014. Por fim a metodologia apresentada foi validada através de diferentes métodos analíticos alternativos presentes na literatura internacional, demonstrando que o Método das Bielas é uma ferramenta bastante atrativa para o dimensionamento de vigas de seção "L" de concreto pré-moldado.

Palavras-Chave: Concreto pré-moldado; Vigas de seção "L"; Método das Bielas; Torção

\begin{abstract}
Among the elements in precast concrete structures, the L-shaped spandrel beams are widely used in the exterior edge of buildings. The three-dimensional geometry and the external loads applied eccentrically on a continuous ledge make this type of section subject to both normal and shear stresses, generating in this way a complex stress state. The fact that the connections with the supports are also subject to torsion makes the design of the spandrel beams one of the most complex among the precast concrete elements due to features that do not occur in the conventional beam models. In this context, this paper aims at presenting the analysis and design of precast concrete spandrel beams using the Strut-and-Tie Method. For this, a numerical example was developed with software CAST covering all design steps and respecting the parameters recommended by ABNT NBR 6118:2014. Finally, the presented method could be validated by comparing with results obtained through different alternative analytical methods present in the international literature, demonstrating that Strut-and-Tie Method is a highly competitive tool for design of precast concrete spandrel beams.
\end{abstract}

Key-Words: Precast concrete; Spandrel beams; Strut-and-Tie Method; Torsion

\section{Resumen}

Entre los elementos presentes en las estructuras de hormigón prefabricado se encuentran las vigas de sección "L", ampliamente usadas en el perímetro de edificios. La geometría tridimensional y las cargas externas aplicadas excéntricamente a la aleta lateral hacen que este tipo de viga se someta simultáneamente a tensiones normales y tensiones de corte, generando así un complejo estado de tensiones. El hecho de que las conexiones con los soportes también estén sujetas a torsión hace que el diseño estructural de las vigas de sección " $L$ " sea uno de los elementos más complejos entre la industria del hormigón prefabricado debido a particularidades que no ocurren en los modelos de vigas convencionales. Con este fin, se desarrolló un estudio de caso con la ayuda del software CAST que cubre todos los pasos del diseño y respeta los parámetros recomendados por ABNT NBR 6118: 2014. Finalmente, la metodología presentada fue validada a través de diferentes métodos analíticos alternativos presentes en la literatura internacional, lo que demuestra que los Modelos de Bielas y Tirantes son una herramienta muy atractiva para el diseño de vigas de sección " $\mathrm{L}$ " de hormigón prefabricado.

Palabras Clave: Hormigón prefabricado; Vigas de sección “L”; Modelos de Bielas y Tirantes; Torsión 


\section{Introdução}

Conforme ilustra a Figura 1, as vigas de seção "L" de concreto pré-moldado são elementos comumente utilizados nas bordas e fachadas que compõem o edifício, seja com a função de peitoril ou como barreira para veículos em edifícios garagem, ou ainda em locais nos quais o topo da viga não pode se estender além do topo da laje, como pontos de passagem entre compartimentos e rampas para veículos em edifícios garagem.

Figura 1: Exemplos de vigas em seção "L".

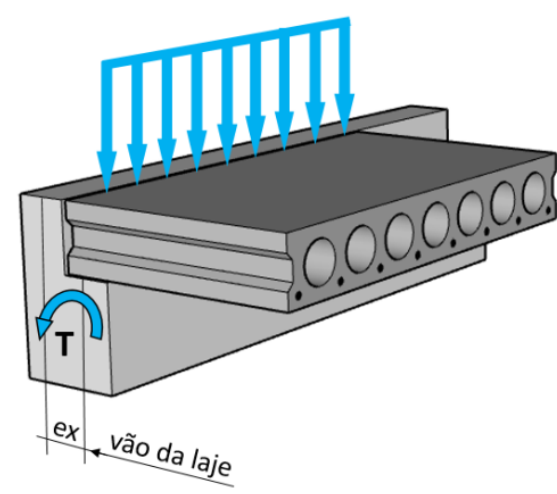

Fonte: Autores.

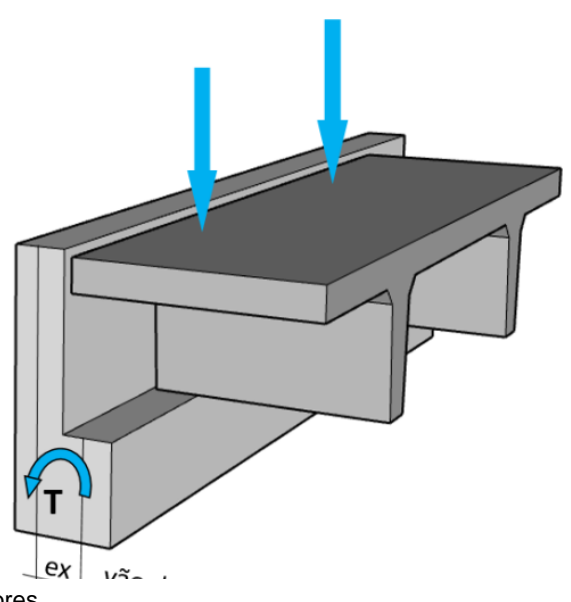

De acordo com Van Acker (2003), as vigas com abas laterais, seção "L" ou "T" invertido, são os tipos mais comuns de vigas para pisos de construções pré-moldadas, sendo a redução da espessura dos subsistemas de pisos a principal vantagem na sua utilização. Destaca-se também como vantagem, o fato deste tipo de viga já possuir a lateral externa acabada, não necessitando de formas para concretagem e solidarização com a laje.

O projeto estrutural das vigas de seção "L" é considerado um dos mais complexos entre os elementos da indústria de pré-moldados, devido a fatores relacionados a assimetria da seção transversal nos dois eixos, a presença de carregamentos excêntricos ao centro de cisalhamento e pelas ligações, que no caso deste tipo de seção transversal, compreende as ligações viga-laje e as ligações viga-pilar (PASTORE, 2015).

Pelo fato da geometria das vigas de seção "L" serem essencialmente tridimensionais, a análise da seção transversal destes elementos possui certas particularidades. Para que o carregamento aplicado na aba lateral seja transmitido para a alma da seção é necessário o dimensionamento de um conjunto de armaduras que suspendam as cargas da base para o topo da viga e promovam uma conexão segura entre a alma e a aba lateral. Por outro lado, o carregamento que atua de forma excêntrica faz com que as vigas de seção "L" necessitem ser dimensionadas à flexão e ao cisalhamento provocado por forças cortantes e principalmente por momentos torsores necessários ao equilíbrio da seção. Essa série de fatores e requisitos mostra que o dimensionamento de vigas de seção "L" de concreto prémoldado não é uma tarefa trivial.

Os principais trabalhos relacionados ao comportamento sistemático das vigas de seção "L" começaram a ser desenvolvidos na década de 80 por Raths (1984) e Klein (1986) motivados por acidentes ocorridos em estruturas pré-moldadas. No campo do dimensionamento merecem destaque os trabalhos de Zia e McGee (1978), Collins e Mitchell (1980), Zia e Hsu (2004) e Lucier et al. (2011b).

Nos últimos anos grande parte dos trabalhos relacionados às vigas de seção "L" estiveram focados em vigas com peitoril alto e delgado para utilização em edifícios garagem, tendo destaque as publicações de Lucier et al. (2011a e 2011b), Hassan et al. (2007), Mercan, Schultz e Stolarski (2010) e Hariharan 
et al. (2019). Para o comportamento da aba lateral destacam-se os trabalhos de Hassan (2007) e Nafadi et al. (2018).

Marti (1985) demonstrou através de um exemplo numérico que o Método das Bielas pode ser uma boa alternativa para a análise e dimensionamento completo de vigas de seção "L", pois é capaz de abranger todas as etapas do processo de cálculo. Através de conceitos da mecânica das estruturas e da resistência dos materiais, o autor propôs uma simplificação para desacoplar o modelo espacial de viga de seção "L", em dois modelos planos, um para aba lateral e outro para seção em elevação, facilitando ainda mais a utilização do método na resolução do problema, conforme ilustra a Figura 2.

Figura 2: Abordagem feita por Marti (1985) para o Método das Bielas em vigas de seção "L".

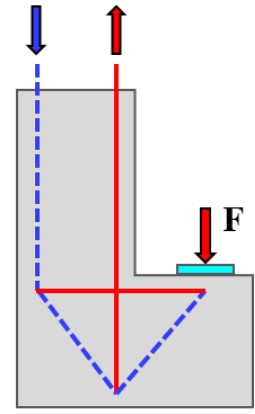

Conto

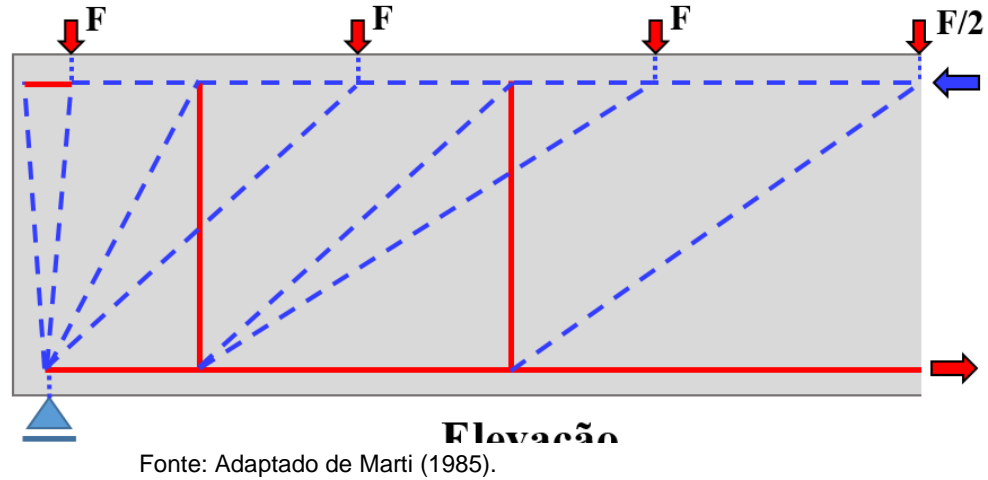

Fonte: Adaptado de Marti (1985).

Basicamente, a essência do método consiste na substituição da estrutura real de concreto fissurada por uma estrutura de treliça equivalente. Estes modelos representam de maneira discreta os campos principais de tensões em que as escoras são formadas por barras comprimidas que representam os campos principais de compressão e os tirantes formados por barras tracionadas que representam os campos principais de tração. As interconexões que promovem a ligação entre as escoras e tirantes são denominadas regiões nodais (EL-METWALLY E CHEN, 2018).

O dimensionamento de elementos de concreto utilizando o Método das Bielas tem se tornado uma tendência mundial principalmente pelo respaldo que as normas e códigos internacionais tem apresentado em suas últimas revisões, como por exemplo as considerações feitas pelo código FIB (CEB-FIP) Model Code (2010), o boletim técnico 61 FIB (CEB-FIP) Design Examples for Strut-and-Tie Models (2013), as diversas possibilidades de utilização apresentadas pela norma canadense CSA 23.3 (2014) e a recente revisão da norma americana ACl:318 (2019) que apresentou doze novas alterações com relação à utilização do Método das Bielas.

Seguindo a tendência dos principais documentos normativos internacionais, a ABNT NBR 6118:2014 passou a apresentar pela primeira vez no item 22.3, ainda que de maneira discreta, procedimentos mais genéricos para aplicação do Método das Bielas, abrindo um leque para novas possibilidades de dimensionamento de elementos estruturais com comportamento mais complexos, como é o caso das vigas de seção "L".

\section{Dimensionamento pelo Método das Bielas}

De maneira a ilustrar o procedimento de dimensionamento de vigas de seção "L" pelo Método das Bielas, será tomado como exemplo a estrutura apresentada nas Figura 3 e 4 . O dimensionamento foi feito considerando a viga na posição final de utilização, inserida em uma classe de agressividade ambiental (CAA II) e os materiais utilizados foram concreto C40 ( $\left.\mathbf{f}_{\mathbf{c k}}=40 \mathrm{MPa}\right)$ e aço CA-50 ( $\mathbf{f}_{\mathbf{y k}}=500$ $\mathrm{MPa}$ ). Os valores de cálculos adotados para determinação da resistência dos materiais utilizados e para os esforços solicitantes foram obtidos para as combinações normais no ELU, conforme as recomendações da ABNT NBR 6118:2014. 
Figura 3: Seções transversais adotadas para o estudo de caso (cotas em centímetro).
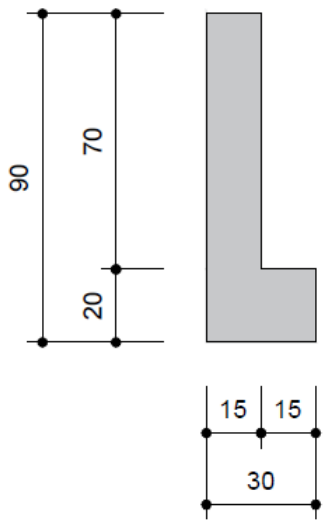

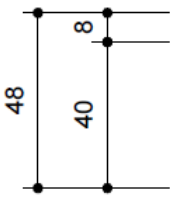

Fonte: Autores.

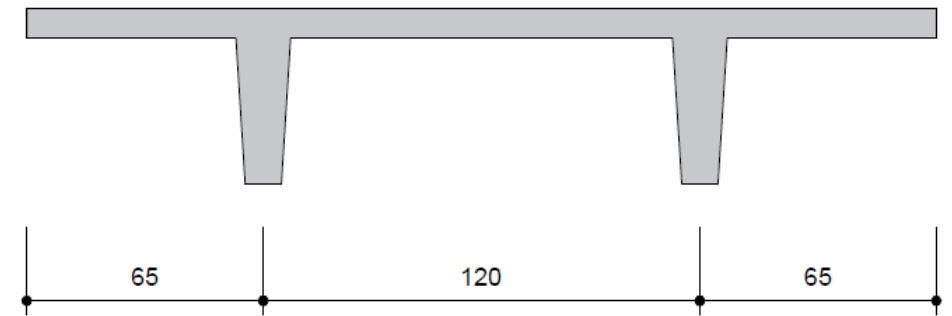

250

Área: $3003,11 \mathrm{~cm}^{2}$

Figura 4: Estrutura em elevação adotada para o estudo de caso (cotas em centímetro).

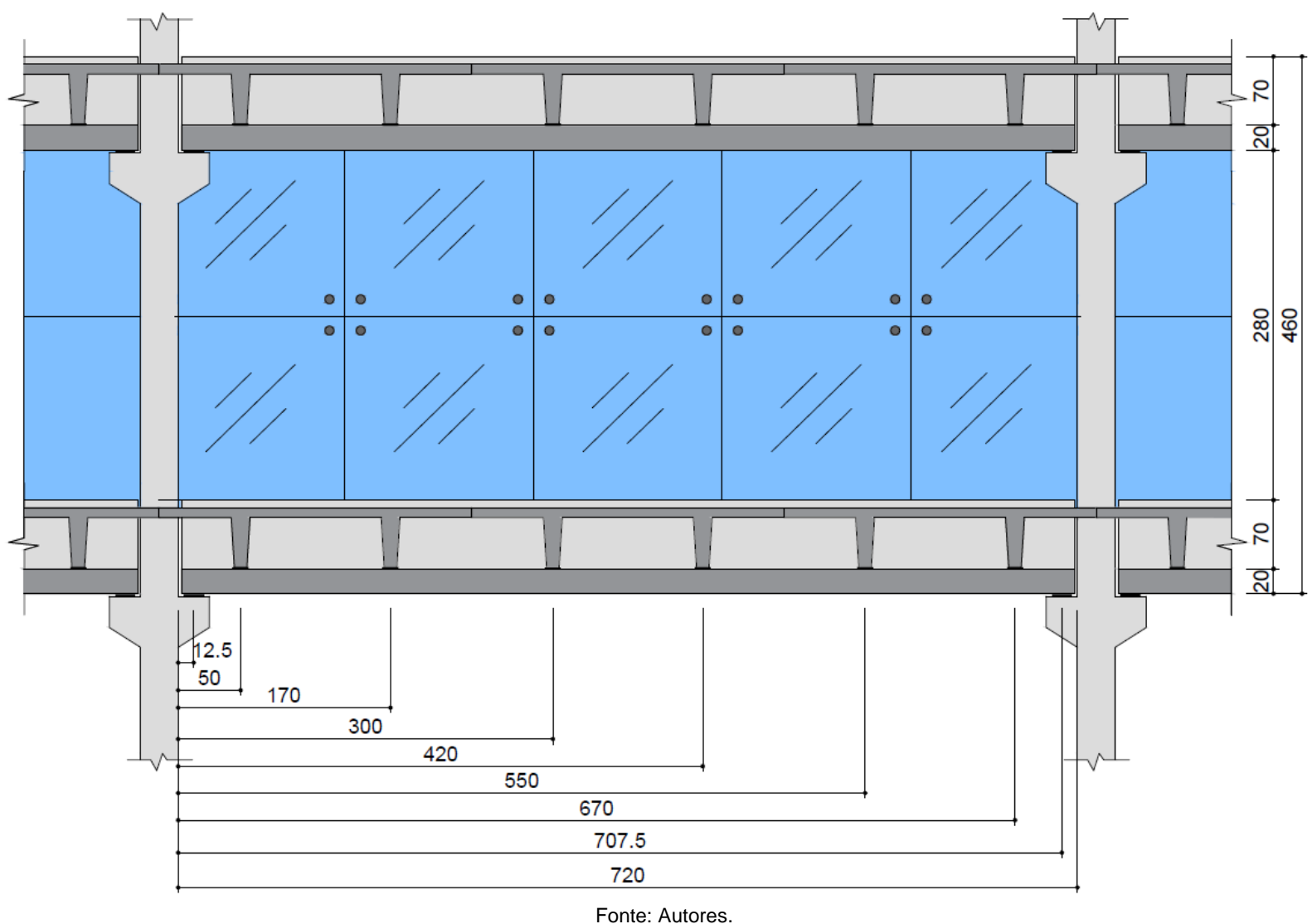

Para determinação dos carregamentos atuantes, considerou-se cargas acidentais de um edifício de escritórios $\left(3,0 \mathrm{kN} / \mathrm{m}^{2}\right)$ e cargas permanentes devido ao peso próprio e capeamento com $3,0 \mathrm{~cm}$ de espessura $\left(25 \mathrm{kN} / \mathrm{m}^{3}\right)$, revestimentos $\left(0,60 \mathrm{kN} / \mathrm{m}^{2}\right)$, divisórias $\left(0,50 \mathrm{kN} / \mathrm{m}^{2}\right)$, forros $\left(0,45 \mathrm{kN} / \mathrm{m}^{2}\right)$ e fachada com pele de vidro $(0,50 \mathrm{kN} / \mathrm{m})$. Considerando os coeficientes $\gamma \mathrm{g}=1,3$ (peso próprio de estruturas pré-moldadas e capa), $\gamma g=1,4$ (demais cargas permanentes) e $\gamma q=1,4$ para a carga acidental, a força concentrada em cada nervura, obtida pela combinação última normal no ELU para um vão de 8,00 metros na laje duplo "T", foi de 57,9 kN.

A primeira etapa do dimensionamento pelo Método das Bielas é a determinação do conjunto de armaduras necessárias para conectar a aba lateral na alma (As,tir) e suspender a força aplicada na base para o topo da seção (As,sus). Considerando o cobrimento da armadura igual a $2,5 \mathrm{~cm}$ e estimando os tirantes verticais e horizontais com diâmetro de $10 \mathrm{~mm}$, a Figura 5 a apresenta as 
dimensões do modelo de treliça adotado na análise e a Figura $5 \mathrm{~b}$ o modelo lançado no software CAST (TJHIN e KUCHMA, 2002) para obtenção dos esforços na treliça e verificação das tensões.

Figura 5: Modelo de treliça para transferência da força aplicada na aba lateral (cotas em milímetro).

a)

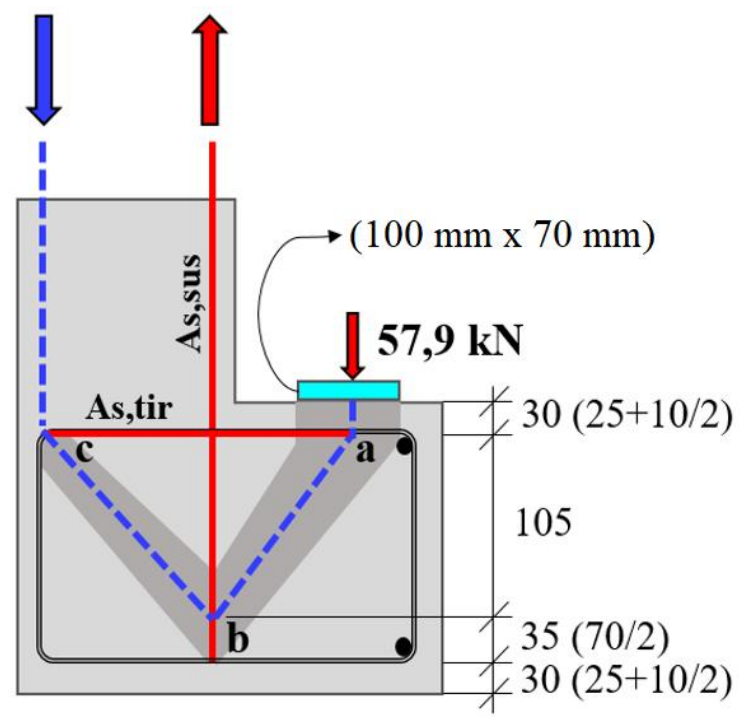

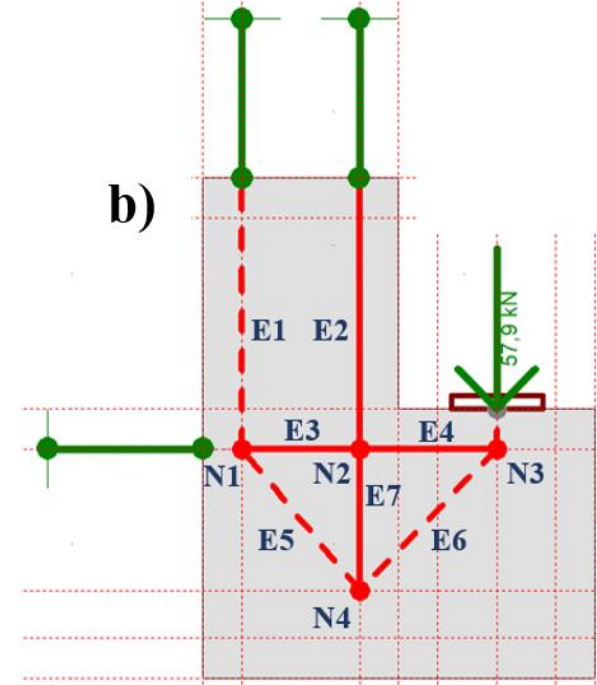

Fonte: Autores.

Seguindo as recomendações da ABNT NBR 6118:2014 para utilização do Método das Bielas, determinou-se a capacidade resistente das escoras e regiões nodais considerando os seguintes parâmetros: $\boldsymbol{\alpha}_{\mathrm{v} 2}=0,84$ e $\mathbf{f}_{\mathrm{cd}}=28,6 \mathrm{Mpa}$. Portanto, os valores limites para as tensões nas escoras e regiões nodais obtidos foram:

$f_{c d 1}=0,85 \cdot \alpha_{v 2} \cdot f_{c d}=0,85.0,84 \cdot 28,6=20,4 M P a$

$f_{c d 2}=0,60 . \alpha_{v 2} \cdot f_{c d}=0,60.0,84 \cdot 28,6=14,4 M P a$

$f_{c d 3}=0,72 \cdot \alpha_{v 2} \cdot f_{c d}=0,72 \cdot 0,84 \cdot 28,6=17,3 \mathrm{MPa}$

Onde:

$f_{c d 1}=$ tensão de compressão máxima para escoras prismáticas e nós CCC

$\boldsymbol{f}_{c d 2}=$ tensão de compressão máxima para escoras atravessadas por mais de um tirante e nós CTT ou TTT

$\boldsymbol{f}_{c d 3}=$ tensão de compressão máxima para escoras atravessadas por um único tirante ou nós CCT

$\boldsymbol{\alpha}_{v 2}=\mathbf{1}-\left(\boldsymbol{f}_{c k} / \mathbf{2 5 0}\right)=$ coeficiente de fragilidade, com $\mathbf{f}_{\mathrm{ck}}$ em MPa

$f_{c d}=f_{c k} / \mathbf{1}, 4=$ resistência à compressão de cálculo do concreto, com $\mathbf{f}_{\mathrm{ck}}$ em MPa

O dimensionamento da armadura de suspensão (estribos verticais) e do tirante horizontal (estribos horizontais) foi feito como base nas forças de tração obtidas nos elementos de barra da treliça, conforme ilustra a Figura 6a. Considerando a resistência de cálculo para o aço $\mathbf{f}_{\mathbf{y d}}=434,8 \mathrm{MPa}$, a área de aço obtida para o tirante horizontal e para armadura de suspensão foram As,tir $=1,33 \mathrm{~cm}^{2}$ e As,sus $=2,88 \mathrm{~cm}^{2}$ respectivamente. Considerando a área de influência das armaduras igual a $60,0 \mathrm{~cm}$, equivalente à metade da distância entre as forças aplicadas na aba lateral, obteve-se as taxas de distribuição As,tir $=2,22 \mathrm{~cm}^{2} / \mathrm{m}$ e As,sus $=4,80 \mathrm{~cm}^{2} / \mathrm{m}$.

Para verificação das escoras foi adotado uma largura de $5,0 \mathrm{~cm}$, para que ficassem confinadas dentro do estribo horizontal, e uma espessura de $60,0 \mathrm{~cm}$, que corresponde à área de influência do conjunto de armaduras. Desse modo, considerando as escoras com uma resistência igual a $\mathbf{f}_{\mathbf{c d} 2}$, os nós 1 , 3 e 4 do tipo CCT e o nó 3 do tipo TTT, obteve-se as relações entre as tensões solicitantes e as tensões resistentes ("Stress Ratio") em todos os elementos, conforme ilustra a Figura 6b. A verificação das regiões nodais foi feita uma a uma separadamente, uma vez que cada nó possui pelo menos três 
faces. O maior valor obtido para o "Stress Ratio" foi no nó N2 que apresentou uma relação de 0,29.

Figura 6: Modelo de treliça para transferência da força aplicada na aba lateral. a) Esforços solicitantes nas barras; b) Níveis de tensões obtidas pelo software CAST nos elementos.

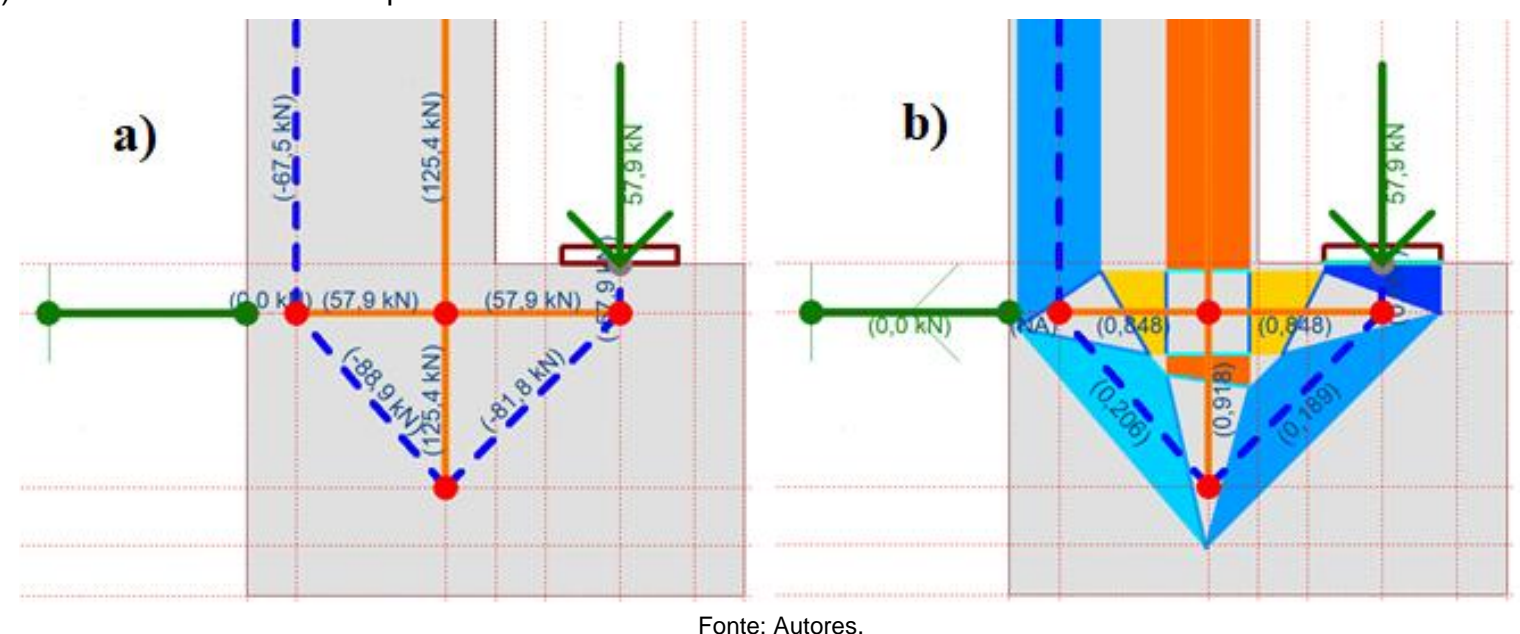

Dimensionado o modelo de treliça em corte, a segunda etapa compreende o dimensionamento da seção à torção. De acordo com as recomendações de Marti (1985), a força de tração de 125,4 kN no ramo direito do estribo vertical irá diminuir linearmente ao longo da altura da viga até o valor de aproximadamente $29 \mathrm{kN}$, que corresponde à metade da força aplicada. Considerando a altura e a largura da seção relativa ao eixo dos estribos $(84,0 \mathrm{~cm} \times 9,0 \mathrm{~cm})$, essa diferença de forças provocará um fluxo de tensões de cisalhamento no ramo esquerdo do estribo correspondente a:

$f_{c}=\frac{F t-0,5 . F}{h_{e}}=\frac{125,4-0,5.57,9}{0,84}=114,8 \mathrm{kN} / \mathrm{m}$

Onde:

$\boldsymbol{F} \boldsymbol{t}=$ força no tirante vertical $(\mathrm{kN})$

$F=$ força externa aplicada pela laje nervurada $(\mathbf{k N})$

$h_{e}=$ altura do estribo vertical $(\mathrm{m})$

Tomando como base a $1^{\text {a }}$ formula de Bredt para torção em elementos de parede fina, metade desse fluxo estará em equilíbrio com o fluxo de cisalhamento torsional de:

$f_{c}=\frac{F \cdot e}{2 \cdot h_{e} \cdot b_{e}}=\frac{57,9.0,15}{2.0,84.0,09}=57,4 \mathrm{kN} / \mathrm{m}$

Onde:

$F=$ força externa aplicada pela laje nervurada $(\mathrm{kN})$

$e=$ excentricidade entre a força externa e o eixo da alma da seção transversal $(\mathrm{m})$

$h_{e}=$ altura dos estribos verticais $(\mathrm{m})$

$b_{e}=$ largura dos estribos verticais $(m)$

A outra metade do fluxo de cisalhamento será transferida através de tensões de cisalhamento transversais no concreto entre os ramos do estribo vertical. As resultantes dessas tensões de cisalhamento transversais estarão em equilíbrio com o fluxo de cisalhamento torsional ao longo da parte fechada do estribo vertical.

Ao longo do ramo esquerdo a resultante das tensões de cisalhamento transversais e torcionais estarão em equilíbrio com a força de compressão de $67,5 \mathrm{kN}$ introduzida acima do ponto $\mathrm{A}$ e com a força de 29 kN no ponto D. A Figura 7 ilustra a hipótese de equilíbrio exposta. 
Figura 7: Hipótese de equilíbrio para a seção transversal (cotas em metros).

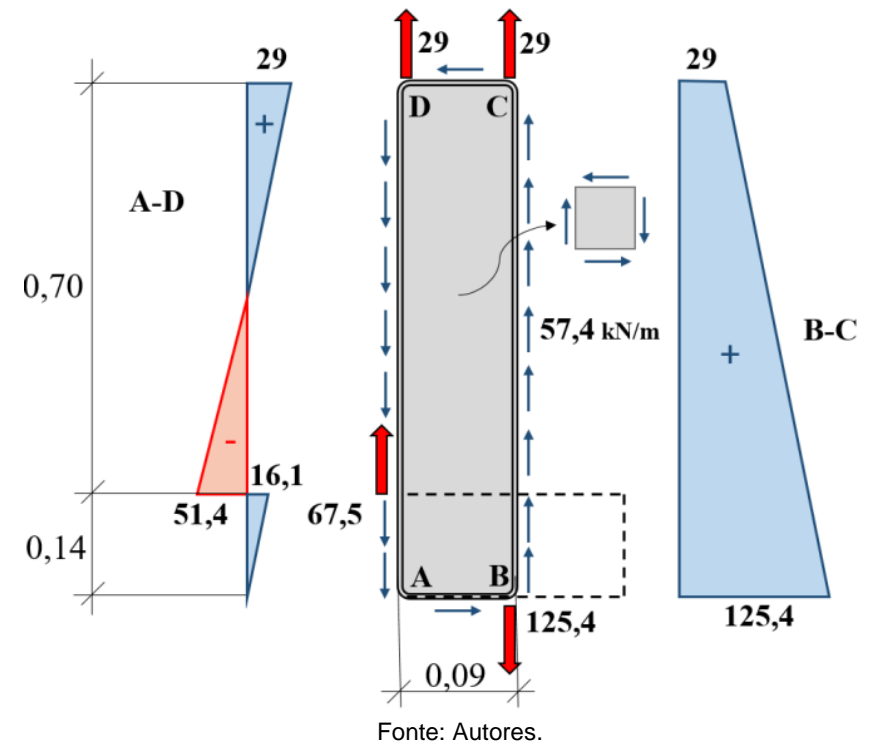

Analisando agora a viga em elevação, assume-se que o momento torsor será transportado até os apoios, pela alma da viga, por um campo de concreto comprimido em espiral através de uma "parede" exterior com o eixo central coincidindo com o eixo do estribo. Neste método, inicialmente é assumido uma certa quantidade de barras longitudinais para resistir aos esforços de tração oriundos da torção para que posteriormente seja possível determinar a armadura transversal necessária.

Considerando barras longitudinais de $10,0 \mathrm{~mm}$ espaçadas a cada $20 \mathrm{~cm}$, totalizando $7,69 \mathrm{~cm}^{2}$ no perímetro dos estribos, obtém-se uma resistência por metro de:

$\rho_{s l}=\frac{100}{e_{l}} \cdot\left(\frac{\pi \cdot d^{2}}{4}\right) \cdot f_{y d}=\frac{100}{20} \cdot\left(\frac{\pi \cdot 0,1^{2}}{4}\right) \cdot 43,48=170,6 \mathrm{kN} / \mathrm{m}$

Onde:

$e_{l}=$ espaçamento entre as barras longitudinais $(\mathrm{cm})$

$d=$ diâmetro das barras longitudinais $(\mathrm{cm})$

$f_{y d}=f_{y k} / 1,15=$ resistência à tração de cálculo do aço $(\mathrm{kN})$

Tomando como base o máximo momento torsor obtido através dos diagramas de esforços solicitantes na região próxima ao apoio da viga $T s d=26,04 \mathrm{kN}$.m, o fluxo de cisalhamento torsional obtido será:

$q=\frac{T_{s d}}{2 . h_{e} \cdot b_{e}}=\frac{57,9.0,15}{2.0,84.0,09}=172,2 \mathrm{kN} / \mathrm{m}$

Ode:

$T_{s d}=$ máximo momento torsor na viga (kN.m)

$h_{e}=$ altura dos estribos verticais $(\mathrm{m})$

$b_{e}=$ largura dos estribos verticais $(m)$

Logo, conforme Marti (1985), este fluxo de cisalhamento torsional requer estribos com uma resistência de:

$\rho_{s w}=\frac{q^{2}}{\rho_{s l}}=\frac{172,2^{2}}{170,6}=173,8 \mathrm{kN} / \mathrm{m}$

Onde:

$q=$ fluxo de cisalhamento torsional obtido na Equação $7(\mathrm{kN} / \mathrm{m})$

$\rho_{s l}=$ resistência por metro obtida para as barras longitudinais calculada na Equação $6(\mathrm{kN} / \mathrm{m})$ 
Obtidas as resistências da armadura longitudinal e dos estribos, é possível obter o ângulo de inclinação das diagonais comprimidas por meio da seguinte expressão:

$\theta=\tan ^{-1} \sqrt{\frac{\rho_{s w}}{\rho_{s l}}}=\sqrt{\frac{173,8}{170,6}}=45,27^{\circ}$

Onde:

$\rho_{s w}=$ resistência por metro obtida para os estribos calculada na Equação $8(\mathrm{kN} / \mathrm{m})$

$\rho_{s l}=$ resistência por metro obtida para as barras longitudinais calculada na Equação $6(\mathrm{kN} / \mathrm{m})$

Por simplificação e segurança, adota-se para o detalhamento das armaduras transversais um diagrama linear de resistência necessária à torção, partindo do centro da viga, conforme ilustra a Figura 8.

Figura 8: Diagrama linear de resistência necessária à torção para armadura transversal.
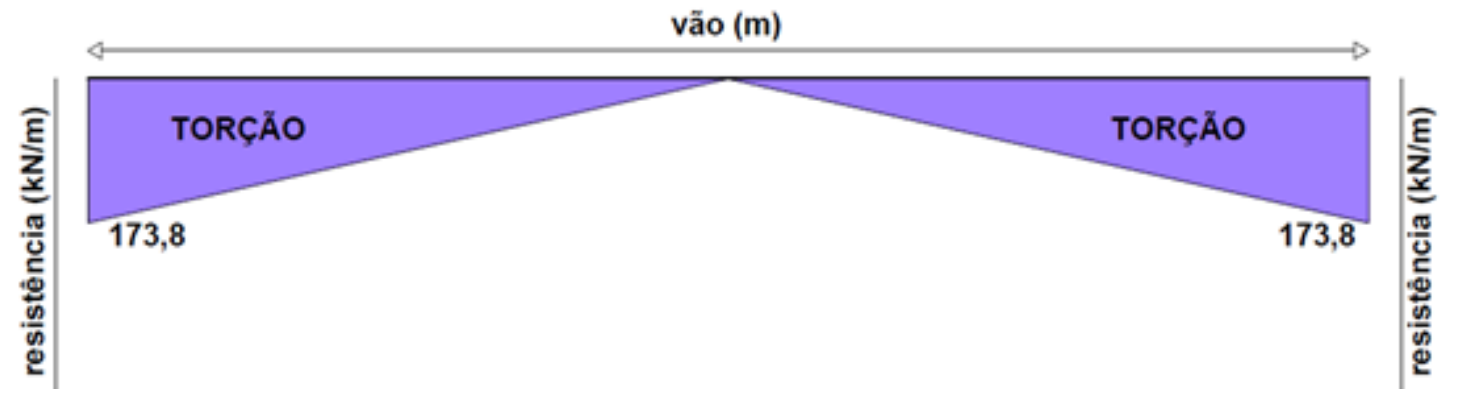

A próxima etapa compreende o dimensionamento da armadura longitudinal principal e da armadura transversal feito por um segundo modelo de treliça em elevação responsável por conduzir as forças externas até os apoios. Neste modelo a concepção da treliça deve ser feita de tal modo que as barras verticais tracionadas fiquem posicionadas em pontos intermediários às armaduras de suspensão dimensionadas anteriormente, desse modo, os esforços obtidos nesta etapa não influenciarão o dimensionamento que já foi feito. A Figura 9 apresenta as nomenclaturas adotadas para os elementos do modelo de treliça em elevação.

Figura 9: Nomenclatura adotada para os nós e barras do modelo de treliça em elevação.

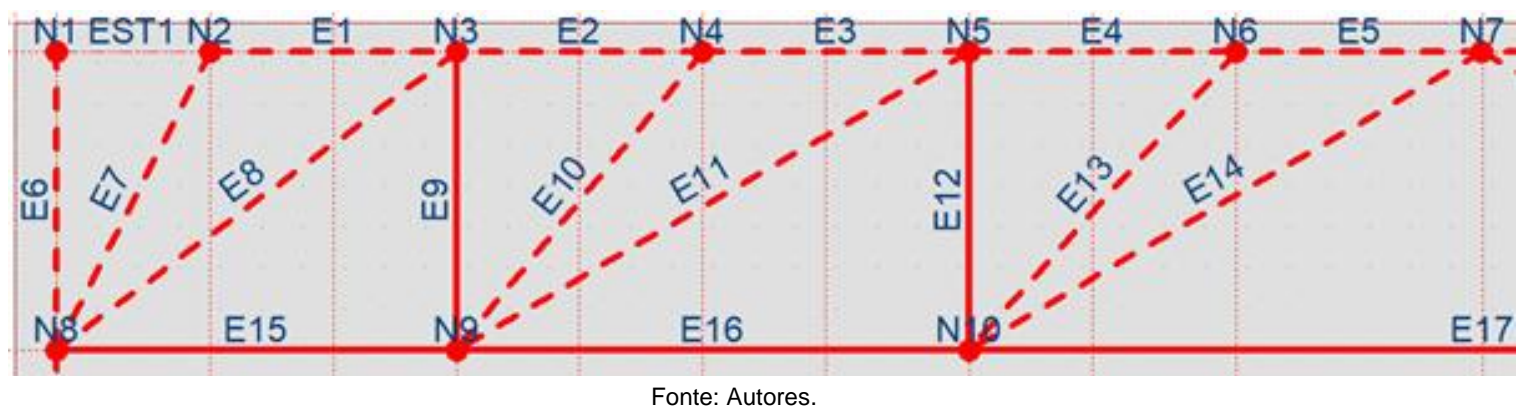

Para o lançamento da treliça, assumiu-se o centroide da armadura longitudinal principal (banzo inferior) no centro do estribo horizontal e para que a inclinação mínima das escoras inclinadas fosse atendida adotou-se inicialmente a distância de $73,5 \mathrm{~cm}$ entre banzos. Como em todo modelo de treliça as forças solicitantes devem ser lançadas nos nós, a carga de cálculo linearmente distribuída na devido ao peso próprio da viga e ao peso da pele de vidro foi substituída por forças concentradas estaticamente equivalentes. Após a análise estrutural do modelo em elevação, obteve-se os resultados conforme ilustra a Figura 10. 
Figura 10: Esforços solicitantes obtidos para o modelo em elevação.

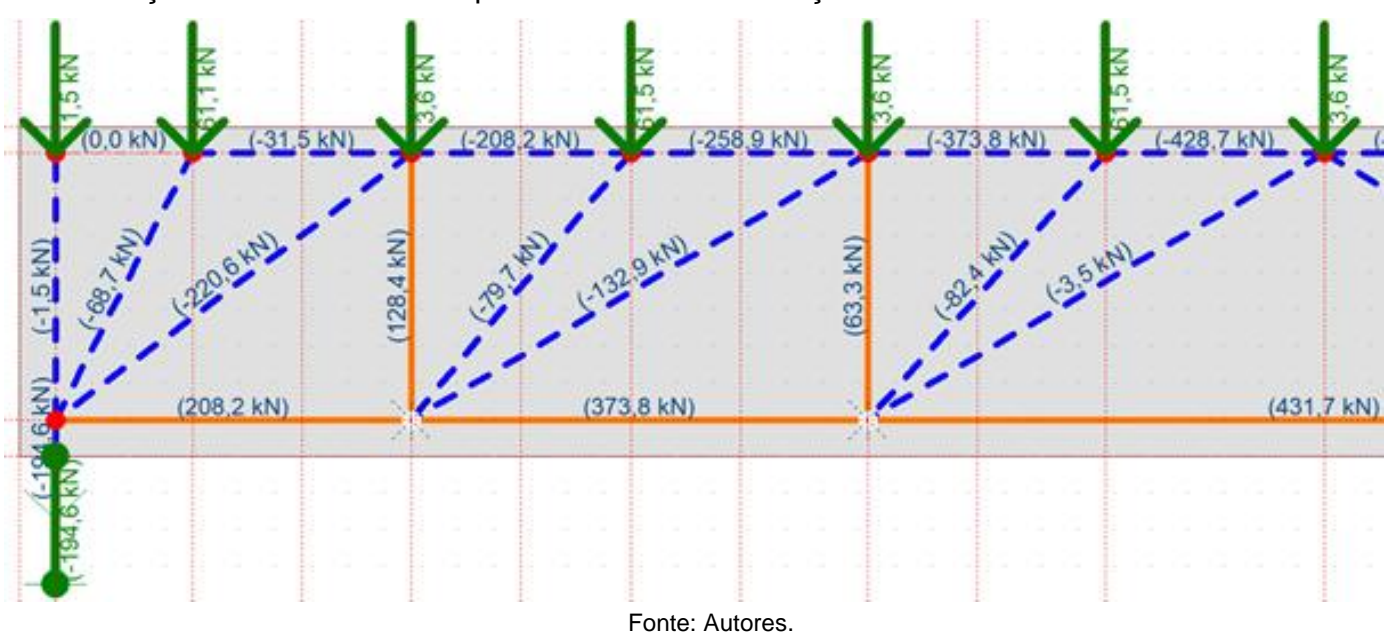

Considerando que na barra E5, onde foi observada a máxima força de compressão (428,7 kN), haverá uma escora prismática com uma resistência igual a $\mathbf{f}_{\mathbf{c d} 1}$, seria necessário um trecho comprimido com uma altura de:

$x=\frac{F_{c}}{b_{w} \cdot f_{c d 1}}=\frac{428,7}{15.2,04}=14,00 \mathrm{~cm}$

Onde:

$F_{c}=$ força máxima de compressão no banzo superior $(\mathrm{kN})$

$b_{w}=$ largura da alma da viga $(\mathrm{cm})$

$\boldsymbol{f}_{c d 1}=$ tensão de compressão máxima para escoras prismáticas e nós CCC obtida na Equação $1\left(\mathrm{kN} / \mathrm{cm}^{2}\right)$

Deste modo, a distância necessária entre banzos seria $90-20 / 2-14 / 2=73,0 \mathrm{~cm}$. Como o valor real ficou próximo do valor estimado inicialmente considera-se que o modelo adotado inicialmente é válido, não sendo necessário fazer novas iterações. Caso o valor encontrado fosse muito diferente do adotado inicialmente, seria necessário adotar uma nova altura para a treliça e a partir dos novos esforços obtidos verificar se o modelo convergiu.

Considerando a força de tração de $430,6 \mathrm{kN}$ no meio do vão e a resistência à tração para 0 aço $\mathbf{f}_{\mathbf{y d}}=$ $434,8 \mathrm{MPa}$, a área de aço obtida para armadura longitudinal principal será $A s=9,33 \mathrm{~cm}^{2}$. Adotando 9 barras de $12,5 \mathrm{~mm}$ foi possível realizar uma distribuição simétrica dentro do estribo horizontal, confirmando a posição do centroide assumida na análise da treliça. Para os tirantes transversais, considerando as forças de tração de $63,3 \mathrm{kN}$ e $128,4 \mathrm{kN}$ foram adotadas armaduras com áreas iguais a $\mathbf{A}_{\mathrm{t}, \mathbf{1}}=0,723 \mathrm{~cm}^{2}$ e $\mathbf{A}_{\mathrm{t}, 2}=1,476 \mathrm{~cm}^{2}$ respectivamente.

Para verificação das escoras e regiões nodais, adotou-se o parâmetro $\mathbf{f}_{\mathbf{c d} 1}$ para as escoras superiores horizontais e o parâmetro $\mathbf{f}_{\mathrm{cd} 2}$ para as escoras inclinadas atravessadas pela armadura de suspensão. A largura adotada para as escoras foi de $14,5 \mathrm{~cm}$ para que se aproveitasse toda a área de concreto disponível no banzo superior. Para o tirante principal representado pelo banzo inferior foi adotada a largura de 20,0 cm que representa a zona de distribuição da armadura. Sendo assim, obteve-se a relação entre as tensões solicitantes e as tensões resistentes ("Stress Ratio") em todos os elementos, conforme ilustra a Figura 11. 
Figura 11: Verificação do "Stress Ratio" no software CAST para o modelo de treliça em elevação.

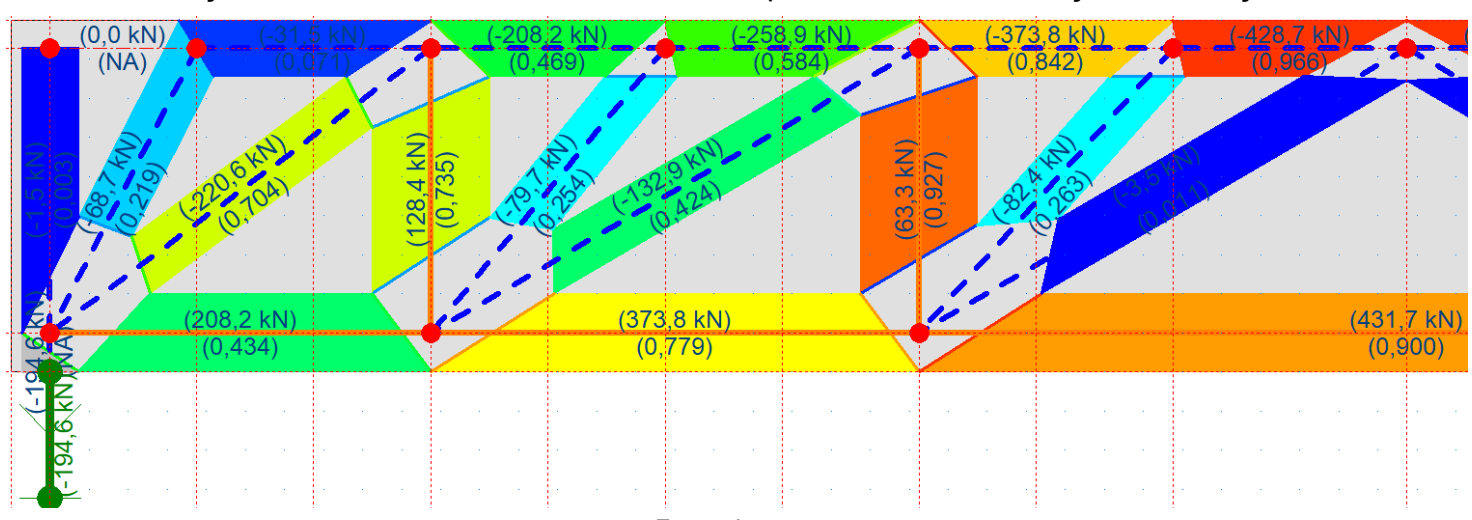

Fonte: Autores.

Nas regiões nodais, os maiores valores obtidos para o "Stress Ratio" foram nos nós N5, N6 e N10 que apresentaram valores superiores ao valor de 0,966 obtido na barra $\mathrm{E} 7$, logo, estes foram considerados os pontos críticos do dimensionamento do modelo em elevação. Por fim, foi traçado o diagrama de resistências necessárias à armadura transversal total $(\mathrm{kN} / \mathrm{m})$ que nada mais é que uma composição dos estribos necessários para os momentos torsores, armaduras de suspensão e forças cortantes, a depender do trecho analisado (Figura 12). Como a viga é simétrica, foi ilustrado as resistências em metade do elemento.

Figura 12: Diagrama de resistências necessárias à armadura transversal (cotas em centímetro).

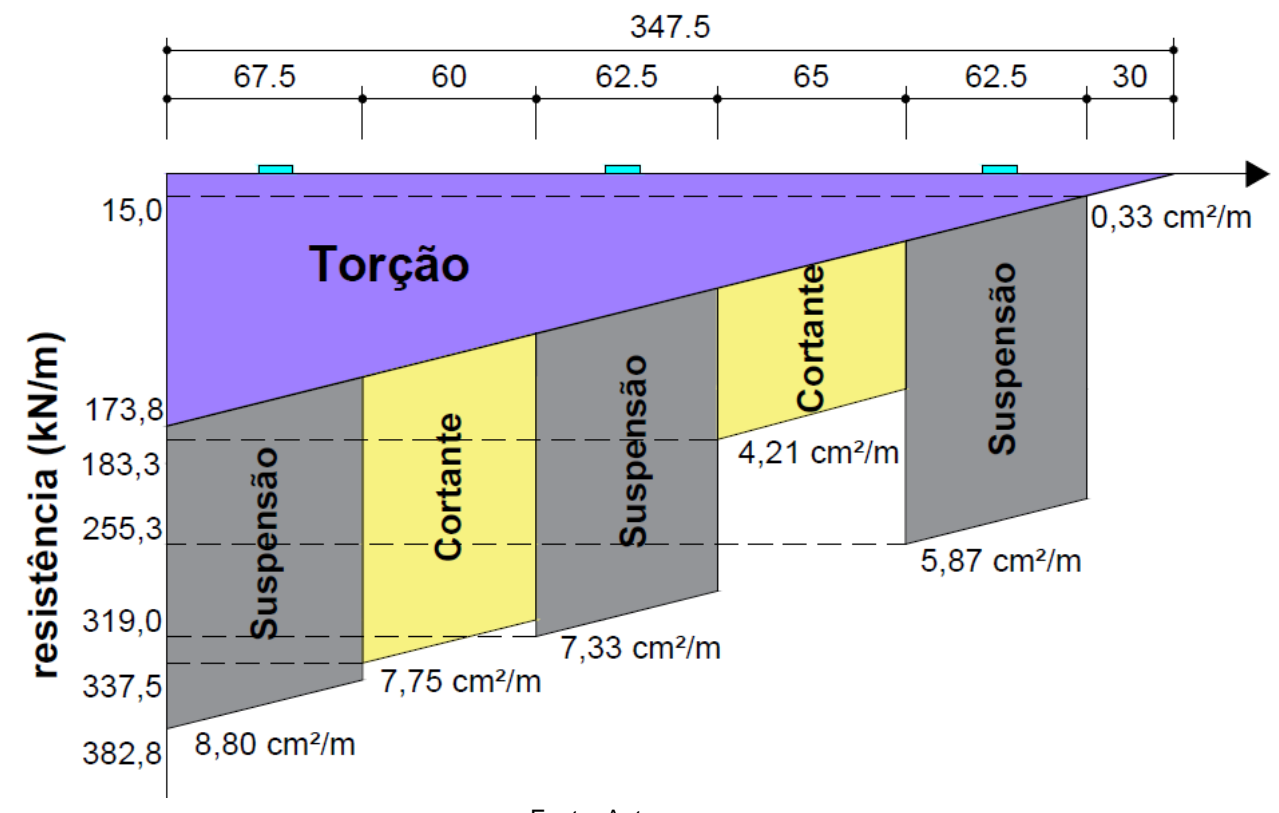

Fonte: Autores.

\section{Dimensionamento da seção via Métodos Analíticos}

Afim de comparar os resultados obtidos pelo Método das Bielas validando a eficiência da metodologia proposta, o dimensionamento da aba lateral e da seção em elevação também foi feito utilizando métodos analíticos reconhecidos internacionalmente.

Para o dimensionamento da aba lateral foram utilizados os métodos analíticos apresentados pelo manual de dimensionamento do BCA (2001) / BS 8110-1:1997, manual de dimensionamento do PCI (2010) e pelas notas do PCA (2013) adaptado às recomendações da última versão do ACl 318:2019, além do recente método proposto por Nafadi et al. (2018) para o dimensionamento da aba lateral à 
punção.

Para o dimensionamento da seção em elevação foram utilizados o modelo convencional de viga recomendado pela ABNT NBR 6118:2014, o método proposto por Collins e Mitchell (1980) baseado no "Compression Field Theory" e o método proposto por Zia e Hsu (2004) baseado em resultados de ensaios experimentais. A escolha destes métodos se justifica pela utilização de estribos fechados para armadura transversal, corroborando com as prescrições da ABNT NBR 6118:2014, e também por serem recomendados por documentos normativos como o CSA A23.3 (2014) e o ACI:318 (2014).

A Tabela 1 apresenta os resultados obtidos em termos da armadura absoluta $\left(\mathrm{cm}^{2}\right)$ e da taxa de distribuição $\left(\mathrm{cm}^{2} / \mathrm{m}\right)$ para armadura horizontal (As,tir) e para armadura vertical de suspensão (As,sus) pelos Métodos Analíticos (MA), além de uma comparação com os resultados obtidos pelo Método das Bielas (MB) de maneira isolada, sem considerar a armadura transversal necessária para as forças cortantes e torção.

Tabela 1: Resultados obtidos para as armaduras da aba lateral.

\begin{tabular}{|c|c|c|c|c|}
\hline Método & $\begin{array}{c}\text { As,tir (cm²) } \\
\text { (MB / MA) }\end{array}$ & $\begin{array}{c}\text { As,tir }\left(\mathrm{cm}^{2} / \mathrm{m}\right) \\
(\mathrm{MB} / \mathrm{MA})\end{array}$ & $\begin{array}{c}\text { As,sus }\left(\mathrm{cm}^{2}\right) \\
\text { (MB / MA) }\end{array}$ & $\begin{array}{c}\text { As,sus }\left(\mathrm{cm}^{2} / \mathrm{m}\right) \\
\text { (MB / MA) }\end{array}$ \\
\hline Método das Bielas & 1,33 & 2,21 & 2,88 & 4,80 \\
\hline Manual do BCA (2001) e BS 8110-1:1997 & $\begin{array}{c}1,11 \\
(1,19)\end{array}$ & $\begin{array}{l}2,77 \\
(0,79)\end{array}$ & $\begin{array}{c}1,33 \\
(2,16)\end{array}$ & $\begin{array}{c}1,11 \\
(4,32)\end{array}$ \\
\hline Manual do PCI (2010) & $\begin{array}{c}0,82 \\
(1,62)\end{array}$ & $\begin{array}{c}0,68 \\
(3,25)\end{array}$ & $\begin{array}{c}1,57 \\
(1,83)\end{array}$ & $\begin{array}{c}1,31 \\
(3,66)\end{array}$ \\
\hline Notas do PCA (2013) & $\begin{array}{c}1,03 \\
(1,29) \\
\end{array}$ & $\begin{array}{c}1,65 \\
(1,34) \\
\end{array}$ & $\begin{array}{r}1,33 \\
(2,16) \\
\end{array}$ & $\begin{array}{c}1,11 \\
(4,32) \\
\end{array}$ \\
\hline
\end{tabular}

Embora a abordagem apresentada para a utilização do Método das Bielas não tenha contemplado, de maneira complementar, a Tabela 2 apresenta os resultados obtidos pelos métodos analíticos para resistência à punção da aba lateral e as diferenças em relação a força solicitante de $57,9 \mathrm{kN}$ aplicada de maneira concentrada.

Tabela 2: Resultados obtidos para resistência à punção da aba lateral.

\begin{tabular}{cccc}
\hline Método & $\begin{array}{c}\text { Resistência à } \\
\text { punção }(\mathbf{k N})\end{array}$ & $\begin{array}{c}\text { Diferença relativa à } \\
\text { força solicitante }\end{array}$ & $\begin{array}{c}\text { Resistência à punção (kN) / } \\
\text { Força solicitante }(\mathbf{k N})\end{array}$ \\
\hline Manual do BCA (2001) e & 87,04 & $47,4 \%$ & 1,50 \\
BS 8110-1:1997 & 122,05 & $106,6 \%$ & 2,11 \\
Manual do PCl (2010) & 154,34 & $161,3 \%$ & 2,58 \\
Notas do PCA (2013) & 62,99 & $6,6 \%$ & 1,09 \\
Nafadi et al. (2018) & \multicolumn{2}{c}{ Fonte: Autores. }
\end{tabular}

Para o dimensionamento da viga em elevação, inicialmente foi determinada a armadura longitudinal principal. Devido a assimetria da seção, de acordo com Pastore (2015), a análise da flexão segundo os eixos principais de inércia pode ser dispensada para vigas de seção "L" com relação h/b maior que 2,5. Sendo assim, o dimensionamento foi feito sem considerar os eixos principais de inércia por meio do modelo convencional de viga recomendado pela ABNT NBR 6118:2014, obtendo-se como resultado um $A s=9,33 \mathrm{~cm}^{2}$.

O dimensionamento da armadura transversal segundo as recomendações da ABNT NBR 6114:2014 foi feito em conformidade com o item 17.7.2.3 que prevê que a armadura transversal total seja calculada pela soma das armaduras calculadas separadamente para força cortante e para torção.

Para força cortante optou-se por escolher o Modelo de Cálculo I para que o ângulo de inclinação das diagonais comprimidas ficasse próximo do ângulo de inclinação obtido pela abordagem proposta por 
Marti (1985) igual a 45,27․ Desse modo, considerando os dois ramos do estribo, a taxa de distribuição obtida para a máxima força cortante $(\mathrm{Vsd}=194,6 \mathrm{kN})$ foi $\mathbf{A}_{\mathbf{v}, 90}=2,18 \mathrm{~cm}^{2} / \mathrm{m}$.

O dimensionamento à torção foi feito considerando a seção transversal composta por retângulos, em conformidade com o item 17.5.1.4.2 da ABNT NBR 6118:2014. A Figura 13 apresenta os modelos adotados para divisão dos retângulos e um terceiro modelo onde foi feita uma simplificação considerando somente a alma da seção como modelo resistente (dimensões em cm).

Figura 13: Modelos adotados para o dimensionamento à torção (cotas em centímetro).
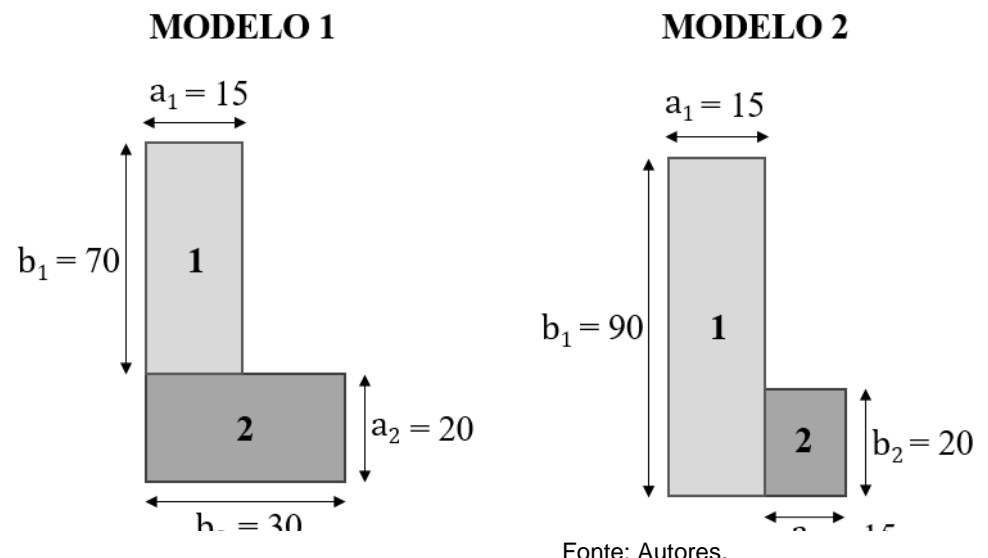

\section{MODELO 3}

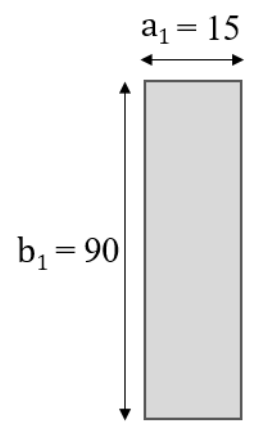

Fonte: Autores.

Distribuindo a armadura transversal de maneira uniforme somente através de estribos verticais, analogamente aos outros métodos analíticos, os resultados obtidos para o máximo momento torsor (Tsd = 26,04 kN.m) nos Modelos 1, 2 e 3, considerando um ramo do estribo, foram: $\mathbf{A}_{\mathbf{t}_{\mathbf{1}}}=7,13 \mathrm{~cm} / \mathrm{m}$; $\mathbf{A}_{\mathbf{t}_{2}}=6,66 \mathrm{~cm}^{2} / \mathrm{m} ; \mathbf{A}_{\mathbf{t}_{3}}=4,18 \mathrm{~cm}^{2} / \mathrm{m}$. Para armadura longitudinal de torção os resultados obtidos foram: $\mathbf{A}_{\mathbf{s l}_{1}}=7,24 \mathrm{~cm}^{2} / \mathrm{m} ; \mathbf{A}_{\mathbf{s l}_{2}}=8,01 \mathrm{~cm}^{2} / \mathrm{m} ; \mathbf{A}_{\mathbf{s l}_{3}}=7,70 \mathrm{~cm}^{2} / \mathrm{m}$.

Como a parcela da força cortante foi calculada para os dois ramos do estribo e a parcela da torção somente para um ramo, a armadura final combinada foi obtida somando-se a armadura calculada para torção com metade da armadura calculada para força cortante. Sendo assim, o resultado final obtido para um ramo dos estribos foi: $\mathbf{A}_{\mathbf{t}_{\mathbf{1}}}=8,22 \mathrm{~cm}^{2} / \mathrm{m} ; \mathbf{A}_{\mathbf{t}_{2}}=7,75 \mathrm{~cm}^{2} / \mathrm{m} ; \mathbf{A}_{\mathbf{t}_{3}}=5,27 \mathrm{~cm}^{2} / \mathrm{m}$.

Adotando o método analítico proposto por Collins e Mitchell (1980) baseado no "Compression Field Theory", foram dimensionadas as armaduras transversal $\left(\mathbf{A}_{\mathbf{t}}\right)$ para forças cortantes e torção combinadas e longitudinal de torção $\left(\mathbf{A}_{\mathbf{s l}}\right)$ para também para os pontos de máximos esforços solicitantes (Vsd $=194,6 \mathrm{kN}$ e Tsd $=26,04 \mathrm{kN} . \mathrm{m})$. Como o método permite uma flexibilidade na escolha dos ângulos de inclinação das diagonais comprimidas também foi adotado 45․ Desse modo, as armaduras transversais obtidas para um ramo dos estribos e as armaduras longitudinais foram: $\mathbf{A}_{\mathbf{t}}=$ $7,29 \mathrm{~cm}^{2} / \mathrm{m}$ e $\mathbf{A}_{\mathrm{sl}}=8,69 \mathrm{~cm}^{2} / \mathrm{m}$.

Por fim, o método analítico proposto por Zia e Hsu (2004) baseado em resultado experimentais e fazendo as mesmas considerações feitas nos outros métodos, os resultados para as armaduras transversais $\left(\mathbf{A}_{\mathbf{t}}\right)$ para forças cortantes e torção combinadas e longitudinais de torção $\left(\mathbf{A}_{\mathbf{s l}}\right)$ foram: $\mathbf{A}_{\mathbf{t}}=$ $7,80 \mathrm{~cm}^{2} / \mathrm{m} \mathrm{e}_{\mathbf{s l}}=8,69 \mathrm{~m}^{2} / \mathrm{m}$.

\section{Comparação entre o Método das Bielas e os Métodos Analíticos}

A utilização do Método das Bielas para o dimensionamento da aba lateral apresentou resultados superiores a todos os outros métodos em termos de valores absolutos para armadura horizontal (As,tir). Já para taxa de distribuição, a diferença de $-25,3 \%$ em relação ao manual do BCA (2001) / BS 8110-1:1997 se justifica pela falta de um consenso para largura de propagação das forças que pode variar de acordo com o método adotado. 
Para as armaduras de suspensão (As,sus), analisando a somente aba lateral, sem considerar a composição final, o Método das Bielas também apresentou resultados superiores a todos os outros. A principal diferença se deu pelo fato de que todos os outros métodos adotam a hipótese de que a força a ser suspensa é da mesma ordem de grandeza da força aplicada pela laje, assemelhando o comportamento da aba lateral a um dente de apoio. Já no Método da Bielas essa força foi $116,6 \%$ superior à força aplicada pela laje, o que justifica tal diferença.

Com relação ao resultado para resistência à punção, observa-se que o recente método analítico proposto por Nafadi et al. (2018) foi o que apresentou a menor previsão de resistência à punção quando comparado com os outros métodos. O forte embasamento experimental que deu origem às equações propostas por Nafadi et al. (2018) demostra que, para uma mesma seção transversal, com as mesmas propriedades dos materiais, as diferenças na previsão da capacidade resistente à punção da aba lateral podem chegar a $154,7 \%$.

Para a armadura final da viga elevação, como a abordagem utilizando o Método das Bielas para armadura transversal é feita de maneira acoplada, os resultados serão apresentados por meio de combinações que somam as taxas de distribuição da armadura transversal e de suspensão considerando os diferentes métodos analíticos abordados, conforme recomendações da literatura.

Os Gráficos 1 e 2 apresentam uma comparação entre os resultados obtidos para as taxas de distribuição da armadura transversal final $\left(\mathbf{A}_{\mathbf{t}}\right)$ e longitudinal de torção $\left(\mathbf{A}_{\mathbf{s l}}\right)$ para as regiões onde ocorrem os máximos esforços solicitantes ( $V s d=194,6$ kN e Tsd $=26,04$ kN.m).

Gráfico 1: Resultados obtidos para armadura transversal total na região dos máximos esforços.

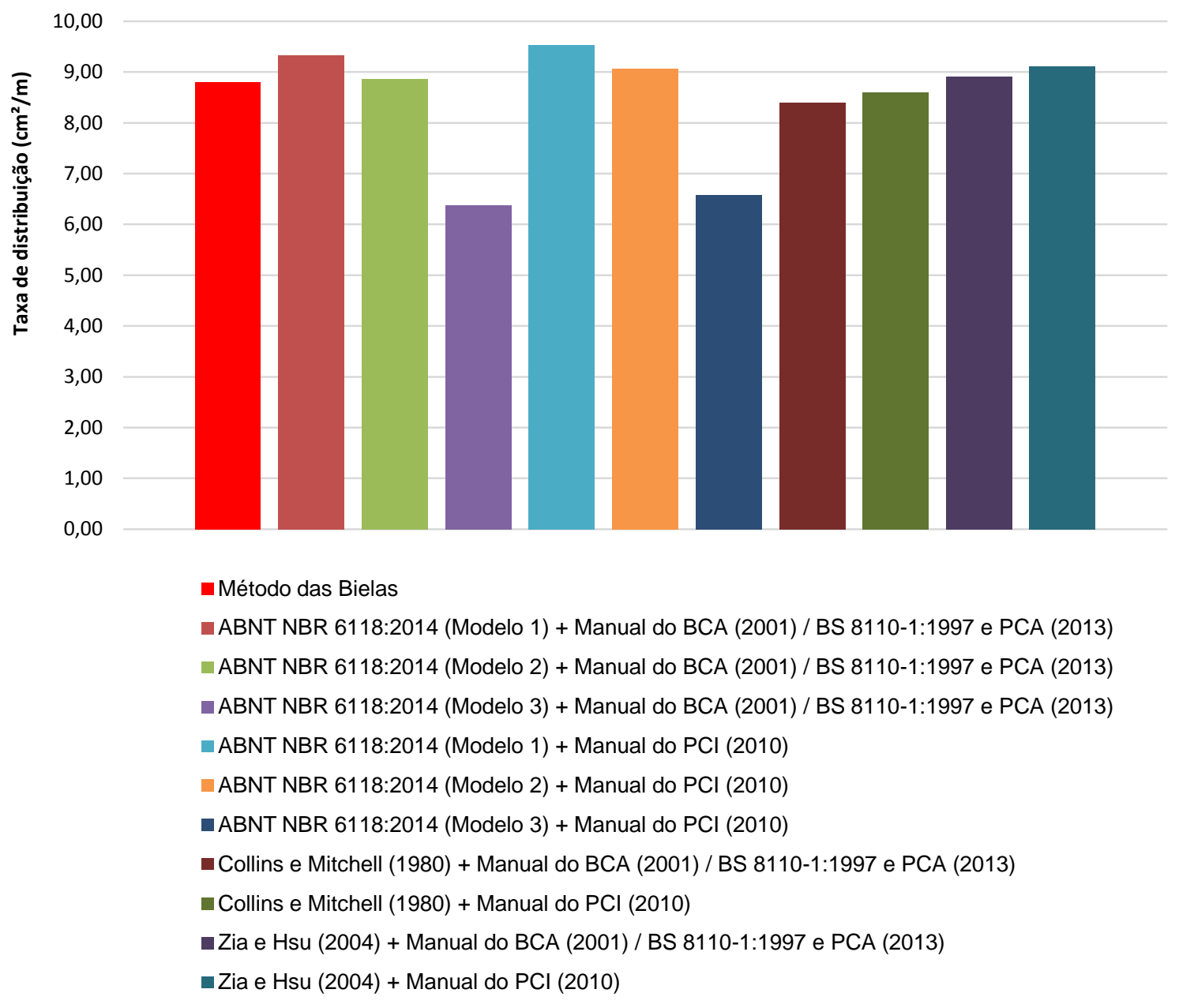


Gráfico 2: Resultados obtidos para armadura longitudinal total na região dos máximos esforços.

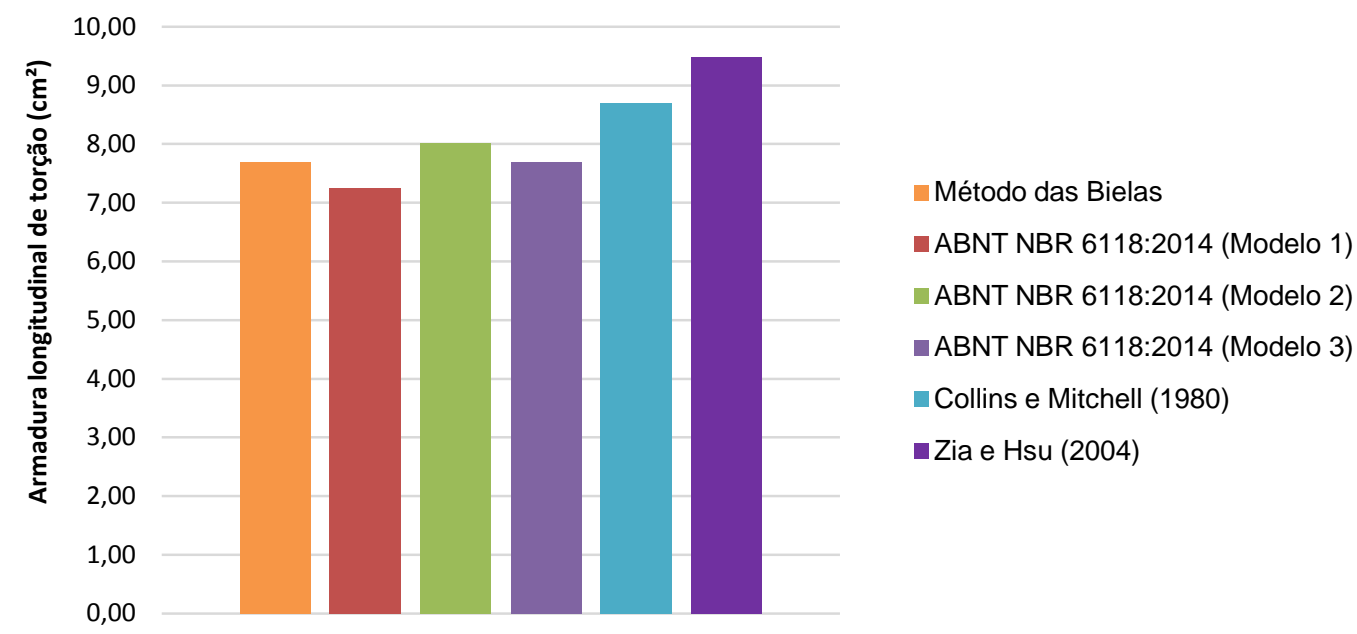

Desconsiderando a simplificação feita no Modelo 3 da ABNT NBR 6118:2014, observa-se que os resultados obtidos pelo Método das Bielas para armadura transversal total foram próximos de todos os outros métodos analíticos comparados, sendo a máxima diferença observada igual a 8,3\% quando comparado com a ABNT NBR 6118:2014 (Modelo 1) + Manual do PCI (2010). Em relação aos modelos analíticos obtidos na literatura internacional, a diferença máxima observada foi igual a 4,5\% quando comparado com o método proposto por Collins e Mitchell (1980) + Manual do BCA (2001) / BS 81101:1997 e PCA (2013).

Para armadura longitudinal os resultados apresentados mostram que o dimensionamento pelo Método das Bielas ficou próximo dos valores obtidos pelo modelo de viga convencional apresentado pela ABNT NBR 6118:2014, sendo a máxima diferença observada igual a 5,9\% quando comparado com o Modelo 1. Comparando com os métodos analíticos alternativos, tanto o método proposto por Collins e Mitchell (1980) como o método proposto por Zia e Hsu (2004) apresentaram resultados superiores aos obtidos pelo Método das Bielas, sendo a maior diferença observada igual a 23,3\%.

\section{Conclusões}

De maneira geral, este trabalho demonstra que a utilização do Método das Bielas segundo as recomendações da ABNT NBR 6118:2014 se apresentou como uma forma alternativa altamente competitiva para o dimensionamento de vigas de seção "L" de concreto pré-moldado submetidas à torção de equilíbrio. $O$ fato das diferenças na armadura longitudinal principal e nas taxas de distribuição da armadura transversal total terem sido inferiores a $8,3 \%$ em relação aos métodos analíticos demonstra que o método está alinhado com as diferentes metodologias presente na literatura internacional, inclusive calibradas por extensos programas experimentais, o que reforça ainda mais a viabilidade da utilização do método neste tipo de elemento. Para armadura longitudinal de torção, os resultados inferiores obtidos para o estudo de caso proposto poderiam ser facilmente ajustados no dimensionamento, uma vez que a metodologia de dimensionamento apresentada para o Método das Bielas permite uma flexibilidade na determinação das armaduras longitudinais.

Vantagens relacionadas a flexibilização no caminhamento das tensões, permitindo tratar furos, aberturas e dentes de apoio em um único modelo, por exemplo, colocam o Método das Bielas à frente das outras metodologias que se limitam ao dimensionamento de seções com condições de contorno mais simples. Um outro ponto forte também foi opção pela utilização de softwares como o CAST, que permitiu a automatização do processo de verificação dos elementos, alavancando a produtividade das 
verificações necessárias para o dimensionamento da seção.

\section{Referências}

ACl COMMITTEE 318. Building Code Requirements for Structural Concrete (ACl 318-19) and Commentary (ACI 318R-2019). Detroit, Ml: ACl Comitee 318, 2019.

ASSOCIAÇÃO BRASILEIRA DE NORMAS TÉCNICAS. NBR 6118: Projeto de estruturas de concreto - Procedimento. Rio de Janeiro: ABNT, 2014.

BUILDING AND CONSTRUCTION AUTHORITY (BCA). Structural Precast Concrete Handbook. 2. ed. Singapura: Technology Development Division of the Building and Construction Authority. 2001.

BRITISH STANDARDS INSTITUTION. BS 8110-1: The structural use of concrete. Part 1: Code of practice for design and construction. London, 1997.

CANADIAN STANDARDS ASSOCIATION. CSA A23.3: Design of concrete structures. Mississauga, Canada, 2014.

COLLINS, M. P.; MITCHELL, D. Shear and torsion design of prestressed and non-prestressed concrete beams. PCI Journal, v. 25, n. 4, 1980.

COMITÉ EURO-INTERNATIONAL DU BÉTON. fib Model Code for Concrete Structures 2010. Berlin, Germany, 2013.

HARIHARAN, V.; LUCIER, G.; RIZKALLA, S.; ZIA, P.; KLEIN, G; GLEICH, H. Behavior of compact Lshaped spandrel beams with alternative web reinforcement. PCI Journal, v. 64, p. 39-54, March - April, 2019.

HASSAN, T. Finite element study of shear behavior of spandrel ledges and comparison with PCI shear design provisions. Advances in Structural Engineering, v. 10, n. 5, 2007.

HASSAN, T.; LUCIER, G.; RIZKALLA, S.; ZIA, P. Modeling of L-shaped, precast, prestressed concrete spandrels. PCI Journal, v. 52, n. 2, 2007.

INTERNATIONAL FEDERATION FOR STRUCTURAL CONCRETE. FIB BULLETIN 61: Design examples for strut-and-tie models. Switzerland, 2011.

KLEIN, G. J. Design of spandrel beams. PCI Journal, v. 31, n. 5, p. 76-124, 1986.

LOGAN, D. R. L-spandrels: Can torsional distress be induced by eccentric vertical loading? $\mathbf{P C I}$ Journal, v. 52, n. 2, p. 46-61, 2007.

LUCIER, G.; WALTER, C.; RIZKALLA, S.; ZIA, P.; KLEIN, G. Development of a rational design methodology for precast concrete slender spandrel beams: Part 1, experimental results. PCI Journal, p. 88-112, 2011a.

LUCIER, G.; WALTER, C.; RIZKALLA, S.; ZIA, P.; KLEIN, G. Development of a rational design methodology for precast concrete slender spandrel beams: Part 2, analysis and design guidelines. $\mathbf{P C I}$ Journal, p. 106-133, 2011b.

MARTI, P. Truss Models in Detailing. Concrete International, v.82, n.1, p. 66-73, 1985.

MERCAN, B.; SCHULTZ, A. E.; STOLARSKI, H. K. Finite element modeling of prestressed concrete spandrel beams. Engineering Structures, v. 32, n. 9, p. 2804-2813, 2010.

NAFADI, M. K.; LUCIER, G. W.; RIZKALLA, S.; ZIA, P.; KLEIN, G. J. Development of design guidelines for ledges of L-shaped beams. PCI Journal. v. 63, p. 32-49, April, 2018. 
PASTORE, M. V. F. Contribuição ao projeto de vigas delgadas de seção "L" de concreto prémoldado. 180 f. Dissertação (Mestrado) - Escola de Engenharia de São Carlos, Universidade de São Paulo, São Carlos, 2015.

PRECAST/PRESTRESSED CONCRETE INSTITUTE. PCI Design Handbook: Precast and Prestressed Concrete. MNL- 120. 7th ed. 2010.

RATHS, C. H. Spandrel beam behavior and design. PCI Journal, v. 29, n. 2, p. 62-131,1984.

VAN ACKER, A. Manual de Sistemas Pré-Fabricados de Concreto. Lausanne: FIB, 2002. Tradução de: Marcelo Ferreira (ABCIC, 2003).

TJHIN, T. N.; KUCHMA, D. A. Computer-based tools for design by strut-and-tie method: Advances and challenges. ACI Structural Journal, v. 99, n. 5, p. 586-594, 2002.

ZIA, P.; MCGEE, W. D. Design for Torsion and Shear in Prestressed Concrete. PCI Journal, v. 19, n. 2, p. 46-65, 1974.

ZIA, P.; HSU, T. T. C. Design for Torsion and Shear in Prestressed Concrete Flexural Members. PCI Journal, v. 49, n. 3, p. 34-42, 2004. 